\title{
Vitamin D: part II; cod liver oil, ultraviolet radiation, and eradication of rickets
}

\author{
Philippe Hernigou $^{1} \cdot$ Jean Charles Auregan ${ }^{2} \cdot$ Arnaud Dubory $^{1}$
}

Received: 22 August 2018 / Accepted: 2 January 2019 /Published online: 9 January 2019

(C) SICOT aisbl 2019

\begin{abstract}
Purpose After Glisson's description of rickets, it took two centuries to realize that rickets was due to the absence of antirachitic nutrients in the diet or lack exposure of the skin to ultraviolet rays. This bone disease caused by vitamin D deficiency was one of the most common diseases of children 100 years ago. This paper explores how the definition, diagnosis, and treatment of rickets shifted in the first decades of the twentieth century.

Material and methods Although benefits of cod liver oil as food were known as early as the seventh century, cod liver oil was only proposed as medicinal for rickets in Northern Europe at the end of the eighteenth century. The relationship between rickets and nutritional deficiency was suspected and demonstrated between 1880 and 1915, at the same time of the discovery of other vital substances (vitamins) needed to prevent beriberi, scurvy, and pellagra. Understanding that the lack of photosynthesized vitamin D or the lack of dietary vitamin D was a similar risk of rickets was an important turn in the comprehension of the disease. We look at the sequence and turn of events related to the discovery of vitamin D.

Results Rickets has been recognized first as a disease of urban living people. Cod liver oil had been used since 1700 as a nonspecific treatment for a range of diseases. Generations of children in cities of the north of Europe had learned to hate the taste and smell of the black oily liquid and then grown up to be parents who, in turn, hated to force it down their children's throats. Occasional papers before 1900 pointed to its efficacy for rickets, and most textbooks of the early 1900s mentioned it only as a treatment option. The discovery in the early 1900s that artificial and natural ultraviolet rays had both antirachitic activity allowed to produce antirachitic foods just by food irradiation with artificial ultraviolet irradiation. Clinical guidelines were adopted to propose exposure to sunlight or to artificial ultraviolet radiation to prevent rickets in children. By the mid-1920s, rickets was promoted as universal, at times invisible to non-experts, but present to some degree in nearly every young child regardless of race or class. It was thus used to promote the young disciplines of preventive medicine, pediatrics, and public health. Innovative advances were made in the understanding of vitamin D synthesis from 1915 to 1935. A public health campaign of the 1930s was a success to eradicate rickets, using irradiated ergosterol from yeast to enrich milk and other foods with vitamin $\mathrm{D}$, ensuring that the general population was consuming sufficient vitamin D.

Conclusion Rickets therefore provides an excellent window into the early politics of preventive health and the promotion of targeted interventions in the world. It is also a relevant historical counterpoint for current debates over the role of risk factors (absence of light or sun) for disease (today's so-called "lifestyle" diseases).
\end{abstract}

Keywords Vitamin D $\cdot$ Rickets $\cdot$ Cod liver oil $\cdot$ Ultraviolet radiation $\cdot$ Sunlight $\cdot$ Rachitis

\section{Introduction}

Philippe Hernigou

philippe.hernigou@wanadoo.fr

1 Hôpital Henri Mondor, 94010 Creteil, France

2 Hôpital Antoine Béclère, 92140 Clamart, France
The name "rickets" comes from the term "wrickken" that, in old English, means "to twist." The more medical word, rachitis, coming from the Greek (spine), was suggested in 1650 by Francis Glisson, both by the similar sound and by the part of the body which, according to him, was one first affected [1]. Resulting from vitamin D deficiency at the period of the industrial revolution, rickets was named "the English 
disease" and was spread and endemic among the poor children of the city. It was a common disease in England during the seventeenth century. Frances Glisson's treatise on rickets published in 1650 described the clinical and anatomic features of rickets in great detail [1]. The exact aetiology of rickets remained elusive until the 1920s. At the turn of the twentieth century, rickets was rife among underprivileged children residing in several polluted European cities and in the industrialized cities of the Northern United States. In 1909, in infants 18 months and younger who died, Schmorl [2] found at autopsy histopathological evidence of rickets in $96 \%$ of cases (214 of 221), highlighting the invasive nature of rickets. Despite its frequency, the exact etiology of rickets has remained elusive. Deficient diet, faulty environment (poor hygiene, lack of fresh air and sunshine), and lack of exercise were all implicated in its aetiology. Animal experimentation, folklore appreciation of the antirickety properties of cod liver oil, and the epidemiological understanding of the geographical association of rickets with lack of sunshine all contributed to solving the puzzle of rickets.

Before 1910, neither diagnosis nor treatment of rickets was standardized. The disease was presented as a disease of "urban living style" people. In the first decades of the twentieth century, clinicians and scientists discovered the two roles of diet and sunlight in the disease's etiology, and both diagnosis and treatment were more standardized, including exchanging bedside diagnosis for radiograph technology and promoting general preventive measures. By the mid-1920s, rickets was designed as a universal disease invisible to non-experts, but present or at risk to some degree in nearly each young child. It was therefore used to promote young disciplines as preventive medicine, paediatrics, or public health.

\section{History of cod liver oil as a treatment of rickets}

The use of fish oils in medicine is mentioned by Hippocrates [3], and Pliny [4] writes that the oil of the livers of the dolphin was used for chronic eruptions of the skin, not only as an external application but also internally.

\section{The Viking experience: cod liver oil as food}

The origin of cod liver oil as food dates back to the Viking period (end of century 700 to 1100 ). Fish liver oil was an important part of the Nordic diet. During the winter months when the days lacked sunlight and were shorter, the Vikings were consuming fish liver oil. The common method to obtain fish liver oil used in Northern Norway was described by Scandinavian Vikings: the water in a large saucepan, like a kettle, was heated to a boil. Birch branches were placed on the pan, and the liver was placed on the tree branches. As the steam rose, they began to cook the liver and the liver oil began to flow into the water. Highly valued for its healing power, strength, and energy, this pure and crude oil was named by the Vikings of Northern Norway as "the gold of the ocean."

\section{First description of the use of liver to treat rickets in 1664 by Thomas Browne}

Apparently, cod liver oil has been used by the fisherman along the coasts of Northern Europe for many years. It is stated that, in the Island of Shetland and the north of Scotland generally, the liver of the cod has long been considered a special delicacy and, hence, is given to invalids and people in poor health, particularly for old pains, and that the fresh oil from the livers was used as butter and considered especially delicious. After the first clear descriptions of rickets published from 1645 to 1668, successively by Whistler, Boot, Glisson, and Mayow [1], many suggestions about treatment were described. Among these treatments is a very interesting comment made by Thomas Browne (Fig. 1) in one of his letters. Sir Thomas Browne (1605-1682) attended the best continental schools (Montpellier, France; Padua, Italy; Leyden, the Netherlands). He received his English medical degree from Oxford in 1637. $\mathrm{He}$ moved in the same year to Norwich, in the county of Norfolk, England, where he practiced medicine until his death 46 years later. "Religio Medici" remains Browne's bestknown work. But, throughout his long professional career, Browne devoted whatever time he could spare from his

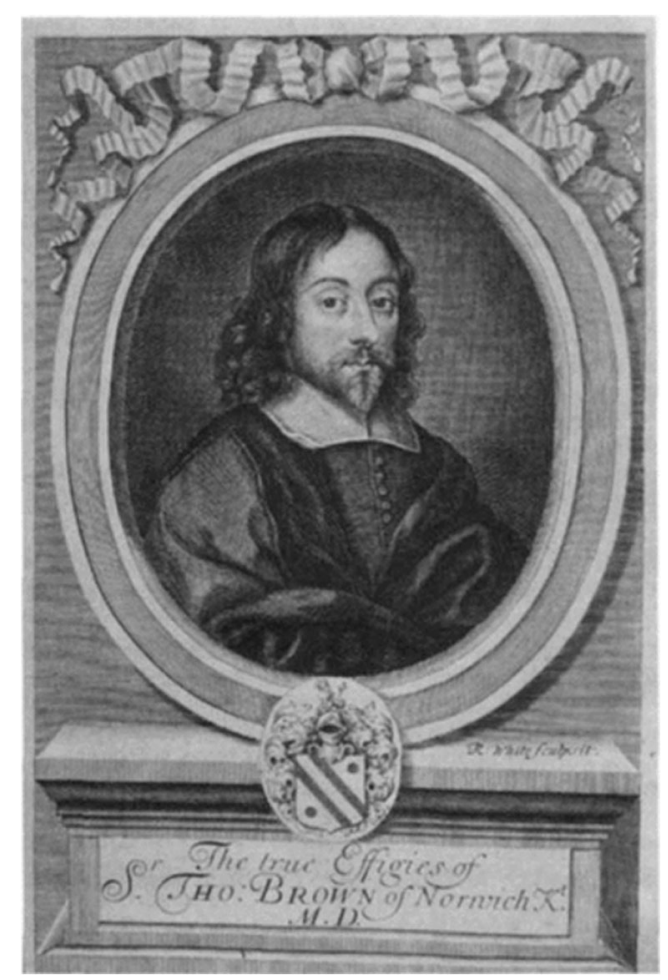

Fig. 1 Portrait of Sir Thomas Browne 
medical practice to observe nature and collect bird specimens in the fields and marshes of Norfolk. In a letter [5] written around 1664 describing birds in Norfolk, he made an interesting comment about the treatment of rickets by food from livers of birds. About rooks (crows), he recorded that "the young ones commonly eaten, sometimes sold in Norwich markets, and many killed for their livers in order to cure rickets." Both Whistler and Glisson had proposed the use of rook liver as a possible treatment of rickets. As Norfolk is on seaside, these birds eventually could eat fishes and probably had a source of vitamin $\mathrm{D}$ in their liver.

\section{Cod liver oil as medicinal in Northern Europe at the Manchester Infirmary}

As far back as the Viking period, Norwegian fisherman frequently rubbed fish liver oil on their joints and muscles to ease soreness. The production of cod liver oil (Fig. 2) was done both for oil lamps and medication. By the 1700s, apothecaries and infirmaries had observed the success of oil treatment; they began to prescribe it to patients suffering from rheumatism. The first written report of the healing effects of cod liver oil (when taken internally) was in a letter (1782) written at the Manchester Infirmary in England by Robert Darbey to Dr.
Thomas Percival [6]. Dr. Thomas Percival (Fig. 3) studied Medicine at Edinburgh University. He did further postgraduate study at Leyden University in Holland and obtained his doctorate (MD) in 1765. Percival had been asked by the Manchester Royal Infirmary to help with an internal dispute and became particularly concerned with the divisions that had arisen among the different branches of the profession - the physicians, surgeons, and apothecaries with their different backgrounds of training (university, hospital, and apprenticeship, respectively). His personality, his interest in sociological matters, and his close association with the Manchester Infirmary (Fig. 4) led to the preparation of a scheme of professional conduct relative to hospitals and other charities from which he drafted the code that bears his name.

Mr. Darbey recounted the events that arrived some years earlier at the infirmary:

"A woman who laboured under the most excruciating rheumatism, and was an outpatient of this infirmary, being advised to rub her joints with the oil, was induced to take it at the same time internally. A few weeks restored her to the use of her limbs, and she was cured. However, little attention was paid to this case, as it was supposed that the alteration of the weather, and the
Fig. 2 Salting and drying cod and, at " $\mathrm{K}$ ", a press to extract cod liver oil (Newfoundland; Engraving 1738)

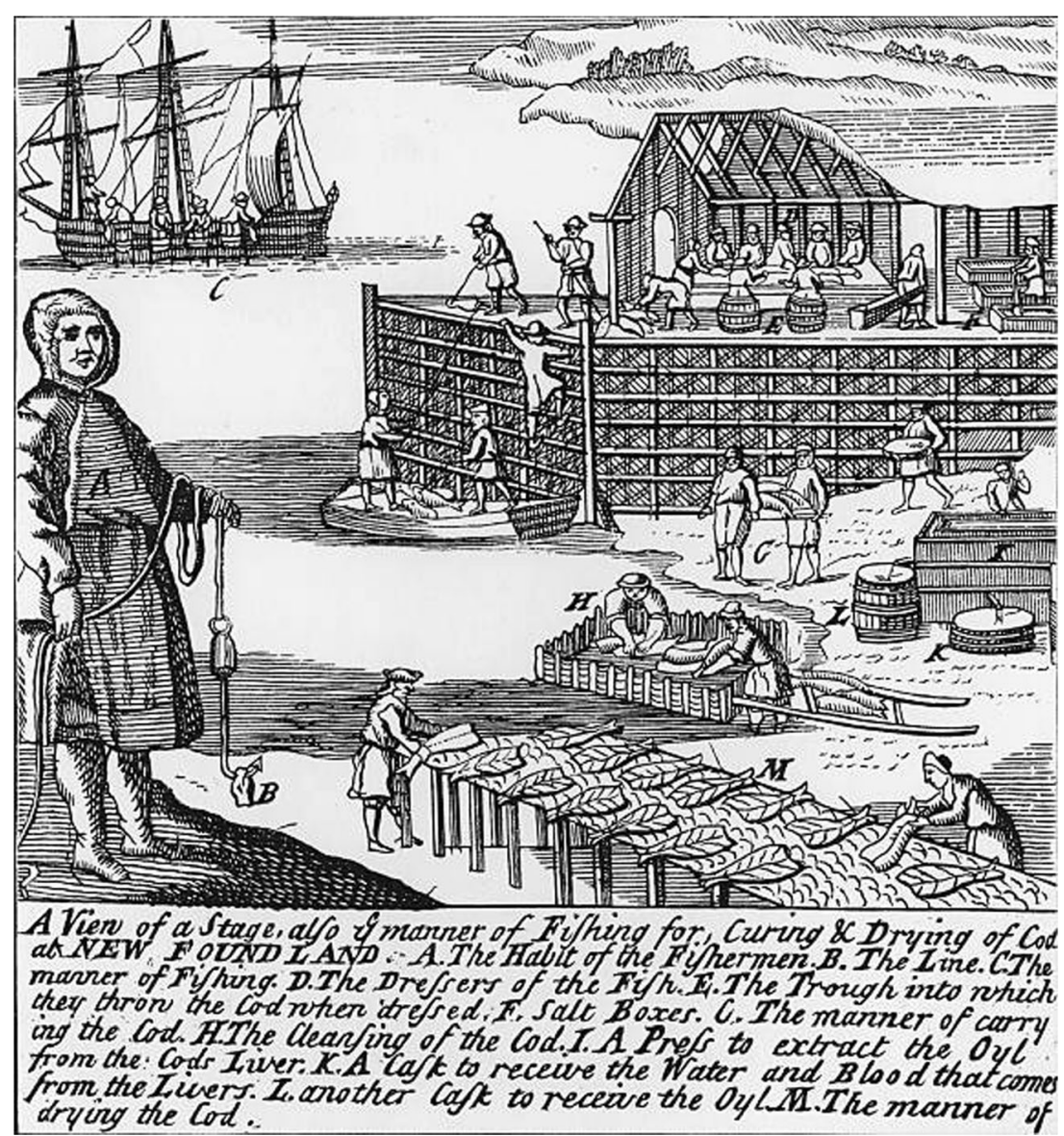




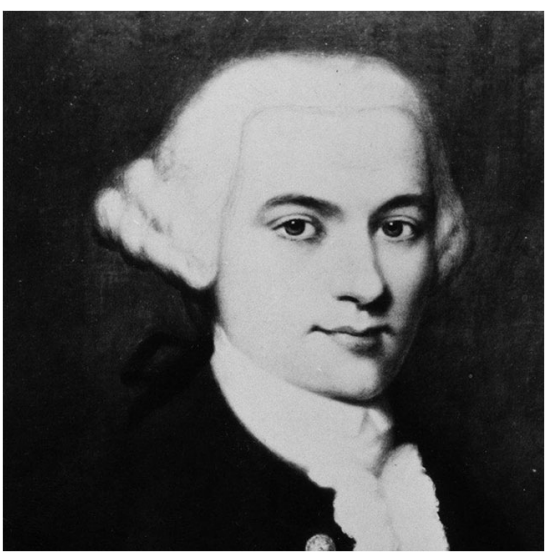

Fig. 3 Portrait of Dr. Thomas Percival

medicine she had before taken, had caused the cure. About a twelvemonth afterwards, her complaints returned with double violence, and the same remedy restored her to health again. Encouraged by this second recovery, Dr. Kay (1766), one of the physicians to the infirmary, prescribed it for other patients, in similar cases; and it answered his most sanguine expectations. Since then, it has been used by the other physicians with the greatest success."

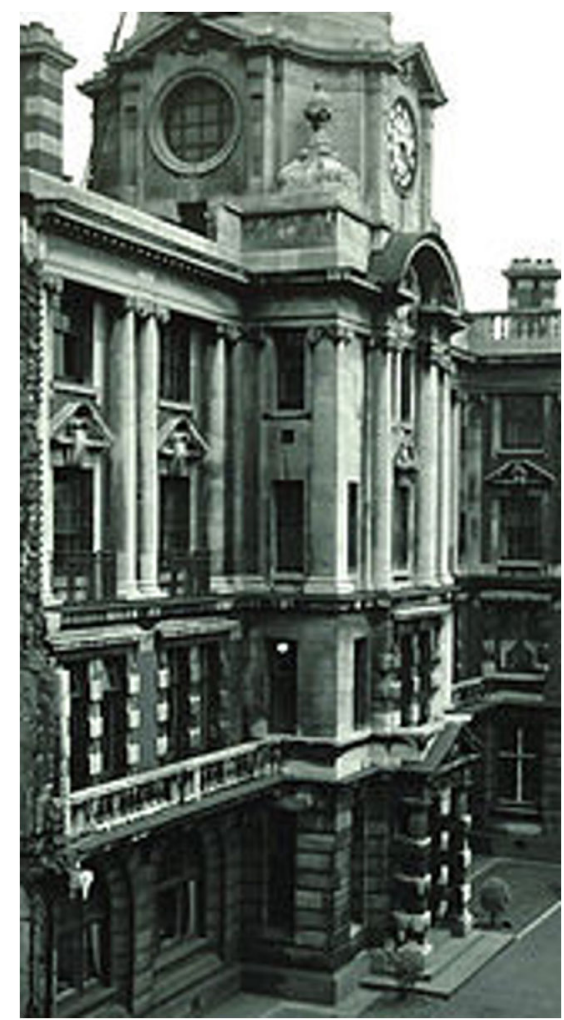

Fig. 4 Manchester Infirmary is a hospital in Manchester, England, founded by Charles White in 1752. It is now part of the Manchester University NHS Foundation Trust, sharing buildings and facilities with several other hospitals
The popularity of cod liver oil for chronic rheumatism became so great at the Manchester Infirmary that "near a hogshead (Whysky barrel of 250 liters) annually" was used there. In 1771, Percival entered it in the British Pharmacopoeia; later, in 1790, he wrote thus of its effect in chronic rheumatism: "While I was one of the physicians to this charity [Manchester infirmary], I had the fullest evidence of the successful exhibition of cod liver oil, in various maladies, of the class above described, which had resisted other powerful modes of treatment. And I frequently compared its operation with that of gum guaiacum, by prescribing each, at the same time, to different patients in similar circumstances. These trials almost always terminated in favour of the oil."

\section{Clinician observations in Europe about efficiency of cod liver oil as treatment for rickets}

\section{In Holland}

Bennett traveling in Europe states that, in Holland, it had obtained a wide reputation for the cure of rickets long before its remedial properties were acknowledged by medical men. In 1822, the Society of Science and Arts of Utrecht made the chemical and therapeutic properties of cod liver oil the subject of a prize essay [7]. Apparently, therefore, its use in scrofula and rickets was known to the Dutch medical profession at that time.

\section{In Germany}

In the same year (1822), Schenck [8] published the first German article on cod liver oil as a therapeutic agent. This article deals with the details of a number of cases of rheumatism and gout which were greatly relieved or entirely cured by cod liver oil. Cod liver oil as remedy against rickets was noted in the German medical literature as early as 1824 by Schutte [9] who first reported of cod liver oil as a treatment of rickets. Schütte, in 1824, published the first definite case histories of rickets cured by cod liver oil, stating that he had used it for 25 years. The cases he cited were in children, from three to five years of age, and unable to walk, who were cured in from five to nine weeks. In each instance, the parents or relatives had prescribed the remedy. He definitely attributed to Percival the introduction of cod liver oil into the medical literature. In 1826 , Schenck [10] reported its successful use in four cases of rickets. He wrote: "I am able to recall that my venerated teacher Michaelis in Marburg recounted to us in his lectures in special therapy, under the chapter on chronic rheumatism, that he had during his stay in England at the hospital in Manchester seen cod liver oil used with striking success against chronic rheumatism." From this time on, numerous German authors wrote on the subject, and cod liver oil became very generally 
used throughout Germany for rheumatism, gout, and rickets and, hence, for scrofula and tuberculosis.

\section{In France}

Cod liver oil was introduced into France a few years later than in Germany. This introduction is described by Trousseau: "The manner in which M. Bretonneau, of Tours, was induced to give the oil in this disease deserves notice. He had treated the rachitic child of a rich Dutch merchant with preparations of iodine and other means, for some time, without success. He was then told by the father that the elder children had previously suffered under the same malady, and had been cured by the cod liver oil, which, in Holland, was a popular remedy. Bretonneau gave the same substance to his young patient, and was much struck with- the very rapid and successful result which followed. He commenced making researches with it on other patients, and it was only then that he learnt for the first time what had been written by the German authors on this subject. He has since given it extensively in rachitis, with the happiest results." This fact was presented in 1837 at the Société de Médecine de Paris by M. Roche. In 1836, de Villards [11] published the first article in France on its therapeutic value but, it was not until Trousseau, about the middle of the century, taught of its use and related the experiences of his celebrated colleague Bretonneau that it became generally known and recommended. Armand Trousseau (1801-1867) published his famous two-volume text Clinique Médicale de l'Hôtel-Dieu in 1861, where he stated that rickets was caused by a faulty diet, and cod liver oil could effectively cure: "Gentlemen, I am also strongly led to believe, that rickets and osteomalacia are the same disease, by the fact, that both are wonderfully combated by the same medication. This medication may be considered as really heroic in the treatment of rickets: it consists in giving cod-liver oil, and, in a more general way, fish oil." The book was translated in English and became famous [12].

The experience was the same in each country. Fishing people were using cod liver oil; then, some physician tried it sometimes, and generally, cod liver oil arrived to be known by the profession. At first, it was used in gout and chronic rheumatism and then in other bone and joint diseases, such as rickets and osteomalacia. However, despite efficiency in rickets and despite this efficacy had been recorded by reputable medical writers, it had fallen in widespread disuse. Unfortunately, Trousseau's remarkable report was largely forgotten by 1900 .

\section{Observations at the London Zoo in 1889}

Bland-Sutton [13] observed rickets among animals (Fig. 5) and, particularly, lion cubs at London Zoo. The affected young animals were living on exclusive diet of boneless lean meat.

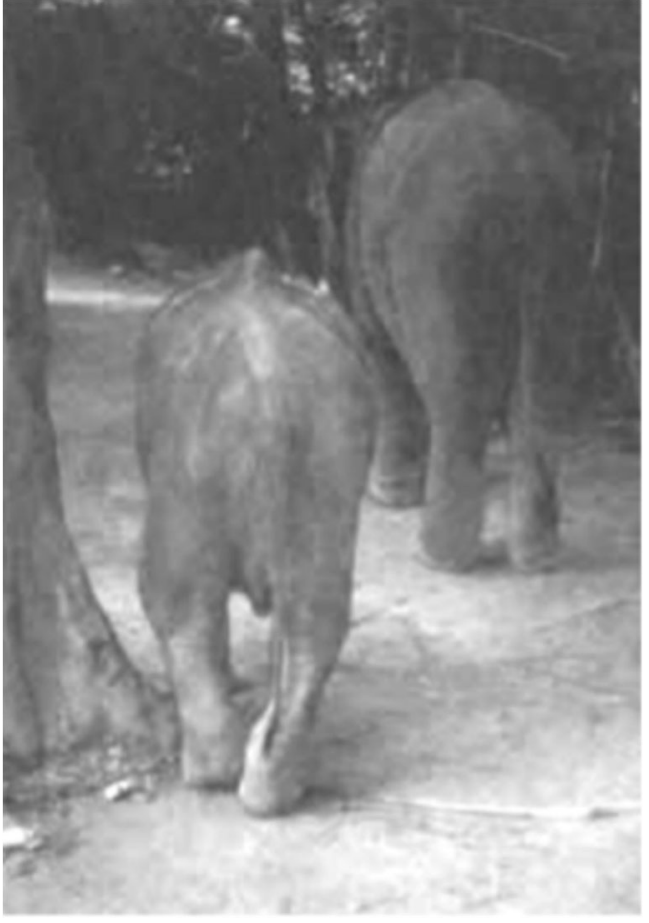

Fig. 5 An elephant mother's milk is the richest of all mammalian milks. Cow's milk is much less nutritious. When captive baby elephants lose their mothers, they are usually fed on powdered cow's milk mixed with rice and bananas. Often, the result is poorly developed bones. This 6month-old elephant has rickets

The addition of crushed bones and cod liver oil to their diet helped the little ones recover fully. The hypothesis of BlandSutton was that rickets was related to deficiency of fat. John Bland-Sutton was the first lecturer on comparative anatomy then later a surgeon in London (at the Middlesex Hospital). Papers were presented in the Proceedings of the Zoological Society; in writing of rickets in monkeys, he recorded "this disease is extremely frequent in monkeys living in captivity in London. Nearly half the total number of monkeys introduced into the Zoological Society's garden die rickety, provided they live a few months after reaching London. The changes in the skeleton develop so rapidly that a capuchin monkey, apparently in good health and thriving well, when introduced into the cages died horribly deformed by rickety changes in four months." It was questioned whether what was described was rickets, because it seems that the situation is quite different in monkeys and in humans and also in other animals. Of course, these observations were made 30 years before progress was made in clarifying diet in rickets.

\section{X-ray technology and Hess study in 1917 demonstrated efficiency of cod liver oil}

Traditionally, doctors diagnosed rickets using a set of clinical signs, including enlarged epiphyses (at the ends of long bones), beading of the ribs (often referred to as the "rachitic 
rosary"), and craniotabes (skull depressions), in addition to the bowed weight-bearing long bones seen in advanced disease. These signs could be subtle and the symptoms nonspecific in mild disease, meaning that different clinicians might assess the same infant differently.

\section{Rapid adoption of X-ray technology for diagnosis}

German physicist Wilhelm Roentgen first detected electromagnetic radiation in the X-ray range in November 1895. X-rays clearly showed problems in the epiphyseal ends of long bones and allowed for positive rickets diagnoses. Even better, lines on $\mathrm{X}$-rays showed new deposits of calcium, giving a visual indication of the healing of rickets when a patient was under appropriate treatment. The use of the X-ray to trace the development of healing process in rickets has made possible definite and accurate observations on the effect of the therapeutic agents used in the treatment of the disease. Fraenkel and Lorey [14] in 1910 published an atlas devoted to rickets; they reproduced X-ray of the bones of rachitic children (Fig. 6) in different stages of healing and relapse. X-ray studies of rickets in both research and clinical practice came to prove the existence of rickets and to test proposed treatments. Even more important, X-rays could find disease before it had appeared clinically. A Boston physician in 1915 published an article [15] in the Journal of the American Medical Association (JAMA), for example, explaining that he had uncovered more than 500 cases of rickets using the new technique of X-ray diagnosis.

\section{Demonstration of prophylactic therapy cod liver oil for rickets}

By 1917, with cod liver oil considered a well-established therapeutic agent, Hess (1875-1933) decided to "investigate whether its usefulness could not be extended to the prophylactic treatment of rickets." The study gave cod liver oil to

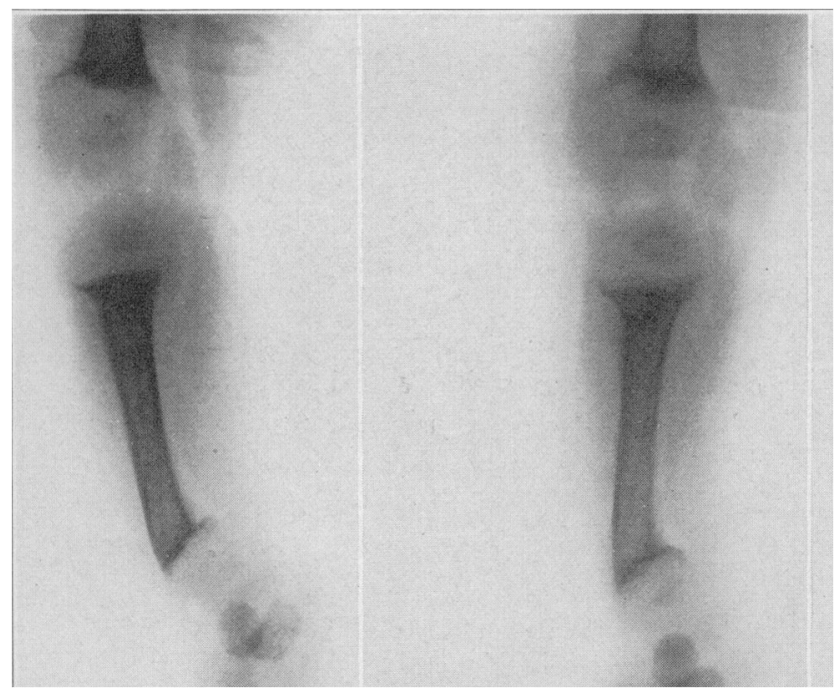

Fig. 6 Radiograph of rickets infants, regardless of whether they had signs of rickets, in one of the first community-based public health experiments in the world [16]. It was done in the Columbus Hill District because difficult economic status, morbidity, and mortality have been observed in this district. Infant mortality across New York City in 1915 was measured, and Columbus Hill had the highest infant mortality of any neighborhood in the city (314 per thousand births). The results of this community-based study were outstanding. Hess (Fig. 7) demonstrated a dramatic improvement in rickets incidence by giving cod liver oil to 80 black infants prophylactically, feeding the children cod liver oil three times daily. More than four fifths of the infants who took the oil for 6 months never developed rickets "though all of them lived under the same conditions and many in the very same families." Hess and Unger published the study results in $J A M A$ and, in light of their results, suggested offering cod liver oil to babies [17].

\section{The slow universal acceptance of cod liver oil: experimental rickets and chemistry}

\section{The teaspoonful of cod liver oil}

Cod liver oil had, of course, been used for centuries as a nonspecific treatment for a range of diseases. Generations of children had learned to hate the taste and smell of the oily liquid and then grown up to be parents who, in turn, hated to force it down their children's throats. Cod liver oil was not desirable for consumption; indeed, it was an abomination, and no one could take it willingly, even once, not to speak when day after day and month after month. The efficient dose was fixed as a teaspoon every day. Nevertheless, people did take it, and the reasonable explanation is that the oil had given strikingly favorable results; "the man with the fish" picture was famous in 1900. His image was embossed and engraved on countless boxes and on bottles of a cod liver oil preparation (Fig. 8a, b). The production was improved particularly about

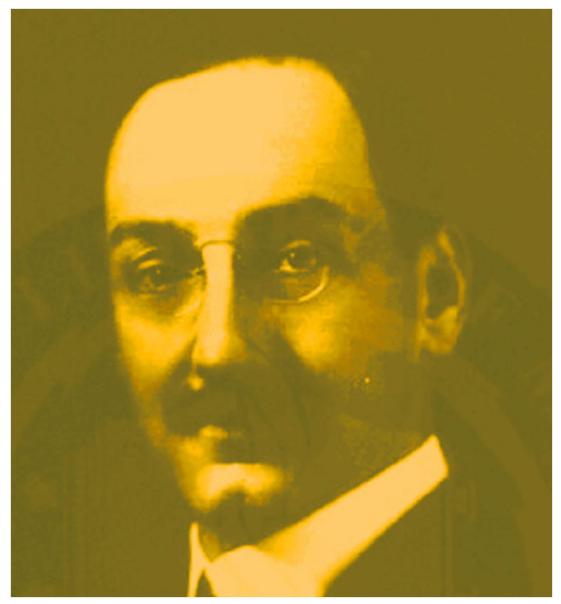

Fig. 7 Portrait of Hess 
Fig. 8 a The man with the fish (1886). b A common codfish, the Gadus morhua, is recognizable on his back by the brown and amber spots on its body (a huge fish with gaping mouth and glassy yellow eye); this image was engraved and embossed on countless boxes and bottles of a cod liver oil preparation; printed in full colour on advertising trade cards, booklets, and posters distributed around the globe a

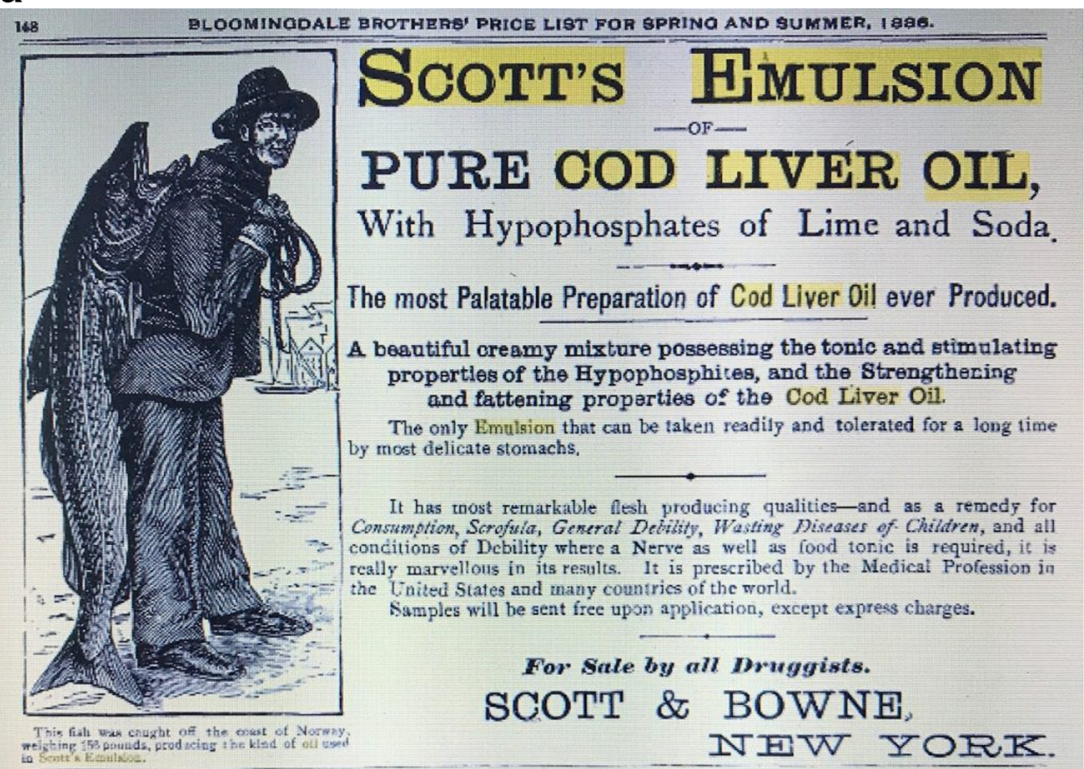

b

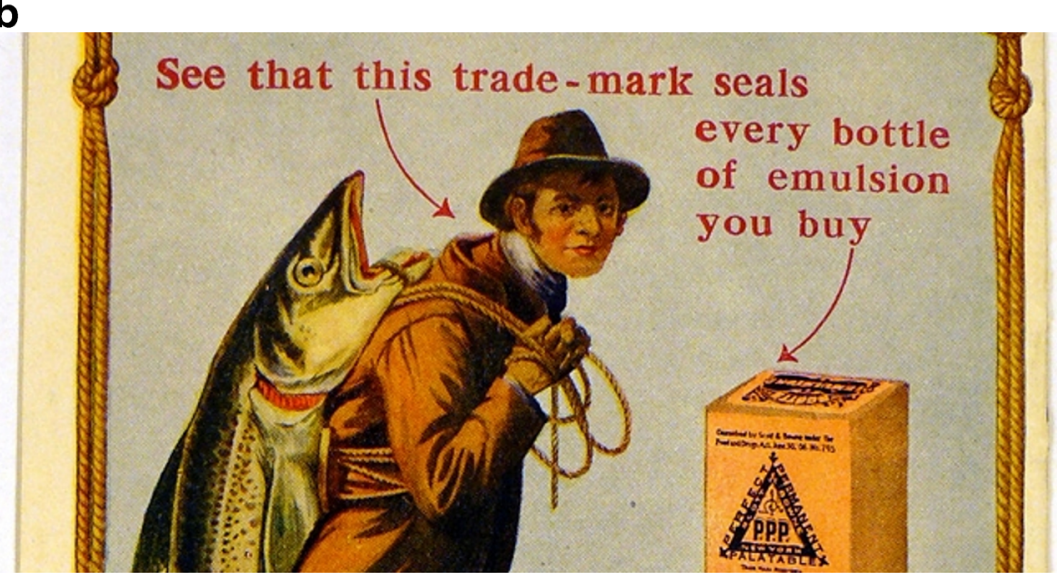

taste and smell (Fig. 9). Occasional papers before 1900 pointed to its efficacy for rickets, and most textbooks of the early 1900 s mentioned it as a treatment option with a teaspoonful of cod liver oil each day (Fig. 10), but its status as a general folk remedy led many in the scientific community to reject it as a specific antidote for rickets. Many of the country's most wellknown physicians, including those most important in the founding of pediatrics as a separate discipline, did original
Fig. 9 Improvement of cod liver oil (1900)



The Lancet:

"Excellent quality. No taste. Of much value in wasting diseases." British Medical inurnal: "Children take it well, tren during the hottest months of the year."

ICEBERG BRAND.

The only Oil in the World guaranteed as made solely from perfectly fresh Livers, and therefore sweet ana pleasant to taste and smell. Guaranteed noncongealable, and not liable to repeat. In Botties only, 1s., 2 s. and 3s. $6 d$. 


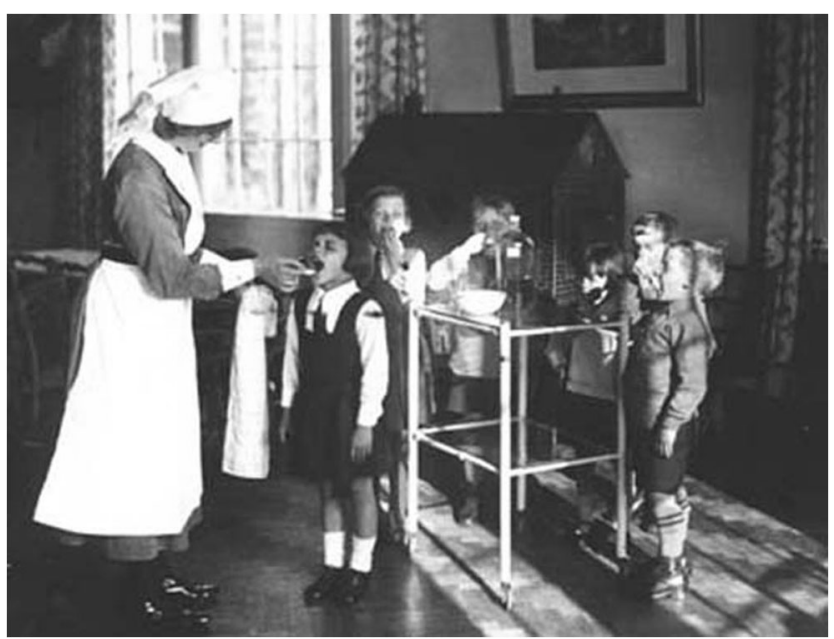

Fig. 10 Distribution of cod liver oil at school (1910)

research on rickets while practicing or teaching. Some of them advocated cod liver oil specifically. However, showing the gap between scientific and clinical medicine and the lack of a standardized approach to treating rickets, this advice on cod liver oil was not always taken.

\section{In the 1919 experimental study on the role of diet in the etiology of rickets}

Edward Mellanby, an English physician [18, 19], conducted in 1919 the earliest definitive study exploring role of diet in the aetiology and treatment of rickets. Rickets was developed easily in dogs that grew on the rachitic diets. Neither yeast (antineuritic vitamin) nor orange juice (antiscorbutic vitamin) hindered the development of rickets. Foods rich in fat-soluble vitamin A as cod liver oil, butter, or whole milk were able to prevent rickets. Mellanby postulated, "It therefore seems probable that the cause of rickets is a diminished intake of an antirachitic factor which is either fat-soluble A, or has a somewhat similar distribution to fat-soluble A." Discerning the nature of dietary antirachitic factor was a next important milestone in the history of rickets. That effort is credited to Elmer McCollum.

\section{Chemistry}

In 1907, Elmer McCollum began a career as a nutritional biochemist in the Wisconsin College of Agriculture (Madison, Wisconsin) [20]. Over the next decade, McCollum improved the biological method of analysis. Nutritive foods were tested using rats as animal model. In 1917, McCollum moved at Johns Hopkins University as the head of the department for chemical hygiene and to pursue his nutritional career. McCollum arrived to induce various stages of malnutrition in rats by modifying restricted diets. Being a scientist, McCollum lacked clinical knowledge to characterize the symptoms and pathology of the various stages of malnutrition that he had induced in experimental rats. By coincidence, McCollum found collaborators that he was seeking. Dr. John Howland [21], who was in 1918 a professor of paediatrics in Johns Hopkins University, asked McCollum whether rickets had been experimentally induced in an animal. Hesitantly, McCollum showed that two of his rats had bony deformities of the thorax and beading of ribs (Figs. 11 and 12). He was thinking that they were possible cases of rickets. McCollum was able to show different rats with similar rachitogenic diets. Convinced that the rats had severe rickets, Howland agreed collaboration with McCollum. Doctors Edward Park and Paul Shipley [22, 23], who were experts in bone histopathology, joined McCollum, and with this team, McCollum was able to progress in his quest to discover the mystery of rickets. McCollum tested various cereal-based diets deficient in fat-soluble vitamin $\mathrm{A}$ on rats and was able to induce skeletal changes similar to those described in rachitic infants. They speculated that the cause of rickets might lie in the deficiency in fat soluble A and calcium in the food or in a disturbance in metabolism of these factors. Shortly thereafter, McCollum observed that by bubbling oxygen through a preparation of the fat-soluble vitamin, they were able to distinguish between vitamin A (which was inactivated) and vitamin D (which retained activity) and predicted several years later that the latter was a vitamin which promotes calcium deposition.



Fig. 11 Appearance of the exterior of the thorax of a normal and of a rachitic rat. The normal one on the left. The rickety rat on the right was small, round shouldered, and had the typical pigeon breast seen in severe cases of rickets in children. The bending inward of the ribs resulted in flattening and deformity of the thorax and the formation of a groove along the line of insertion of the diaphragm 
Fig. 12 Appearance of the inside of the thorax of a normal rat and also one suffering from rickets. On the right, the rickety rat is seen to have great deformity of the thorax. There are large knobs on the ribs due to spontaneous fracture and attempt at healing. The junctions of the ribs with the cartilages are enlarged, and the ribs are bent inward at their ventral extremity. The beaded condition of these is the analogue of the "rachitic rosary" seen in children

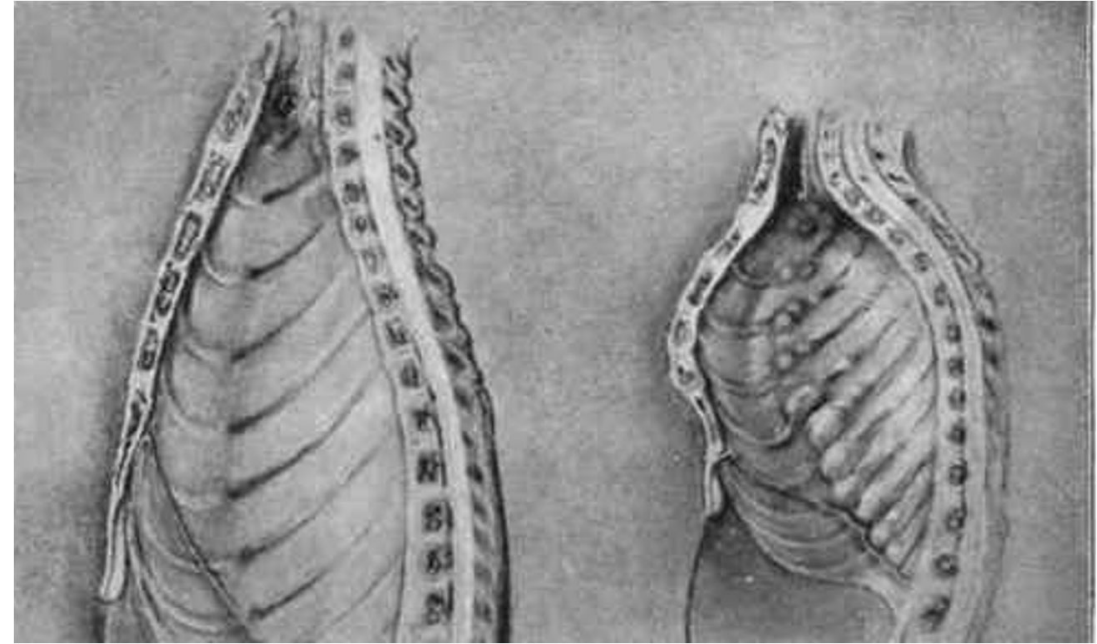

\section{Sunlight and ultraviolet radiation for the treatment of rickets}

\section{Jędrzej Śniadecki in 1822: the first mention of sunlight's role in the cure of rickets}

There was a mention of sunlight's role in the cure of rickets, by Jedrzej Śniadecki in 1822, who noted less rickets in children from rural districts of western Poland [24]. Jędrzej Śniadecki (Andrew Sniadecki) was a Polish physician born in Żnin in the Polish-Lithuanian. He was also a writer, biologist, and chemist. His achievements in chemistry included the modern Polish terminology. Śniadecki (1768-1838), after completing university studies, was chosen as the first professor of both medicine and chemistry (Fig. 13). It was named at the Grand Duchy of Lithuania's, as a professor of main school which was renamed in 1803 Imperial University of Vilna. Śniadecki was one of the main organizers of the actual

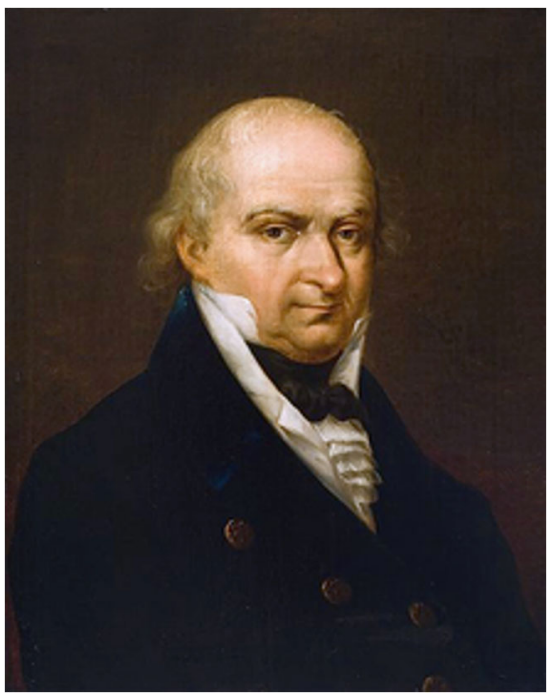

Fig. 13 Portrait of Andrew Sniadecki
Wilno Medical-Surgical Academy. From 1806 to 1836, he was the head of the Medical Scientific Society in this region.

Śniadecki wrote about rachitic children in the densely populated, narrow, and dark city streets, but the accuracy of his observation was only recognized a century later. Mozolowski quotes Śniadecki in his 1822 book On the Physical Education of Children as saying that the direct action of the sun was important in the cure and prevention of rickets [25].

\section{Theobald Palm theory: the absence of sunshine as a cause of rickets}

Theobald Adrian Palm (Fig. 14), born in Colombo (Ceylon), was the son of Scottish Presbyterian missionaries. After the end of Edinburgh University School Medicine, he chose the

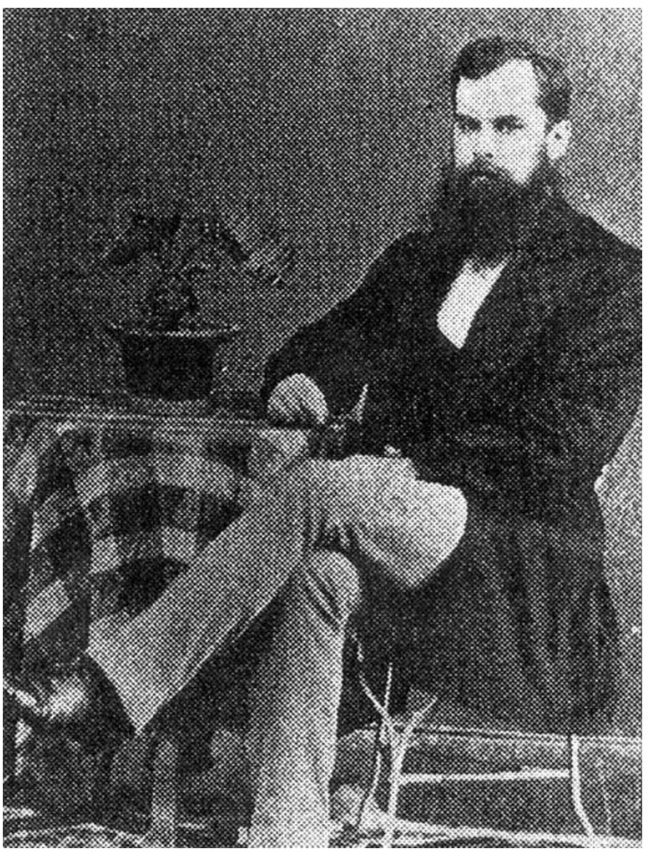

Fig. 14 Portrait of Theobald Adrian Palm 
Edinburgh Medical Mission. After, he moved in 1875 to Niigata, a treaty port of Japan, where he spent ten years. While in Japan [26], Palm noted that rickets disease was absent, in contrast to the UK. If Palm had remained medical missionary in Japan, he might not had made observations he did about rickets and sunshine. However, he returned in 1884 to practice in England. He went specifically in Wigton, Cumberland (northwest of England), not far from Carlisle, and west of Tyne coal mining district. There, Palm noted many rachitic children and began his inquiries. While in Germany, August Hirsch [27] had created maps of rickets zones, and he chose to emphasize air quality, crowding, and even the soil. Palm, at contrary, focused upon the sun. When living in Birkenhead (near Liverpool), he saw children with rickets. In a letter [28] to the British Medical Journal, he first wrote in 1888 on the "want of light." Palm speculated that therapy for rickets should include "systematic use of sun baths."

From the epidemiologic map where the prevalence of rickets was published in 1889 by a Collective Investigation Committee under the supervision of British Medical Association, he noted that rickets was frequent in "large towns or thickly peopled districts" [29]. Theobald Palm wrote more details about his observations [30] after he had collected information from three different sources. First, he assembled replies from medical missionaries from the southeast region of Asia and from North Africa. Second, he looked at the topography of rickets in England based upon medical research reports. Third, he analyzed rickets rates in the other parts of Europe. The geography of rickets involved the European temperate latitudes of Holland, Germany, England, France, Belgium, and Northern Italy. Southern Spain, Southern Italy, Greece, and Turkey "enjoy notable immunity." He recommended scientific observations on the effects of sun on health, use of sunbaths, and relocation of rickets to areas where sun is common [30].

\section{Artificial light as a treatment of rickets}

Although Palm's observations were ignored by most of doctors, some accepted the observation that sun might be efficient: a natural heliotherapy centre for tuberculosis was established at Leysin (Swiss Alps) in 1903 by Auguste Rollier to treat patients by exposure to sunlight. Rollier [31] empirically recognized benefit of heliotherapy for cure of rickets. In 1912, Jan Raczynski correlated the relation which exists between the incidence of rickets and the lack of sunlight. He pointed that the curve of a number of cases who were admitted to the hospital rose sharply in January, which reached maximum in May and fell in June [32]. Raczynski reported an experiment he had performed with two puppies born in May of the same mother. One was exposed to the sunlight from the morning to the evening, while the other one was kept in darkness. Both puppies were nursed by the mother. At the end of six weeks, both were killed for examination. The one which had received light was normal whereas the other kept in darkness had not assimilated the mineral salts that were necessary for the formation of a skeleton. However, sun was absent in many geographic areas and the idea that sun could be changed by artificial light was proposed.

\section{First utilization of artificial light with an incandescent lamp by Buchholz}

As early as but in 1904, Buchholz [33] reported the curing of 16 rachitic children with the rays of glühlicht [33]. Glühlicht may be translated as glow light or incandescent light. Although this was not known by Buchholz, compact fluorescent lamps have the potential for emitting some ultraviolet light. We do not know exactly what kind of incandescent light was used by Buchholz, but at this period, there was a research on these lamps: in 1897, the German chemist and physicist Walther Nernst invented the Nernst lamp, an incandescent lamp with a ceramic globar; this lamp did not require vacuum or inert gas and was as efficient as a carbon filament lamp. Nernst lamps were popular until overtaken by lamps with metal filaments [34]. On December 1904, Hungarian Sándor Just and Croatian Franjo Hanaman obtained a Hungarian patent for tungsten filament lamp. This lamp lasted longer with the brighter light than with the carbon filament. Tungsten filament lamps were marketed in 1904 by the Hungarian company Tungsram. There is high probability that Buchholz used one of these two lamps.

\section{Kurt Huldschinsky: the quartz mercury-vapor lamps and the ultraviolet irradiation}

Kurt Huldschinsky (Fig. 15), a Berlin pediatrician, was able, during World War I, to demonstrate three fundamental points that allow the progress of the treatment after the war. He demonstrated (1) that sunlight could be changed for an artificial light; (2) that in the artificial light, ultraviolet irradiation was efficient; and (3) that after irradiation of the skin, a chemical substance was probably synthesized in response to UV light and could diffuse throughout the affected child.

\section{Irradiation with artificial light}

During World War I, the German and Austro-Hungarian empires were under a stiff blockade imposed by the British navy, and food for civilians was totally inadequate. Rickets became even more prevalent in children in wartime. In Berlin, even older children and young adolescents developed rickets. At that time, half of German children probably suffered from rickets. It was already known that the disease needed 


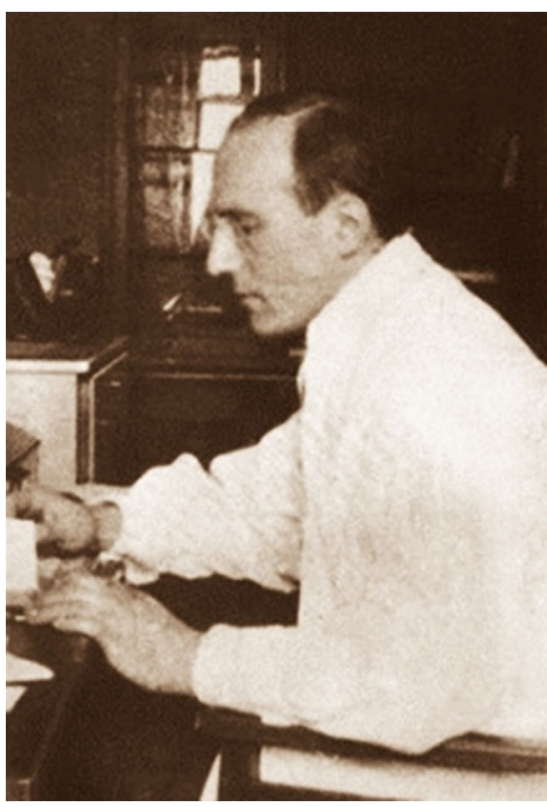

Fig. 15 Portrait of Kurt Huldschinsky

correction of calcium deficiency and sun. Kurt Huldschinsky noted the pale skin of his patients. He provided them with calcium supplements and irradiated them with a quartz mercury-vapor lamp (Fig. 16) and then announced a cure $[35,36]$. This cure for rickets was rapidly confirmed in 100 other children [37].

\section{The wavelengths of the lamp ranged from 200 to $600 \mathrm{~nm}$ (UVB wavelengths are 290-320 nm)}

At this period, the biochemical mechanism triggered in the human dermis by the sun's electromagnetic radiation was not fully understood, and scientists were exploring mostly the long wavelength (red) end of the spectrum which emits wavelengths ranging from 200 to $600 \mathrm{~nm}$ (UVB wavelengths are 290-320 nm). The quartz mercury-vapour lamp used by Huldschinsky was a recent German innovation. The efficiency of mercury lamps is dependent on operating conditions of the lamp. When the amount of mercury is very small, the spectrum of the low-pressure lamp is in the ultraviolet (an order of

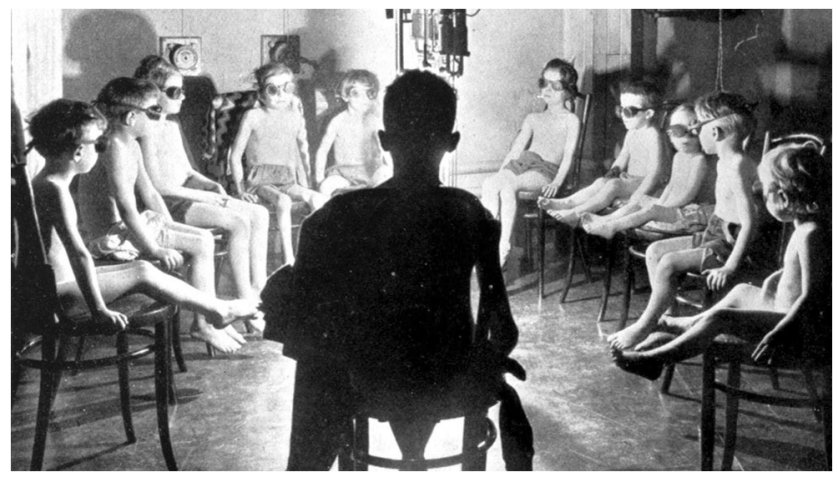

Fig. 16 Children treated with a UV lamp
$90 \%$ from 187 to $254 \mathrm{~nm}$ ). This wavelength range was demonstrated as very efficient to destroy undesirable bacteria; sterilization lamps were available before 1911 commercially. The next step in mercury lamps was the development in quartz technology, arriving at the beginning of the twentieth century [38]. The first lamps were constructed from ordinary glass. The development of quartz allowing high transparency for ultraviolet allowed lamps with better optical properties and greater heat resistance [38]. The high temperatures that were tolerated by quartz resulted in high efficiency of the lamps. It was noted that improved ultraviolet transparency requires care to avoid exposure of eyes. In 1905, Schott $[39,40]$ described the uviol lamp (Heraeus quartz) which transmitted ultraviolet down to $253 \mathrm{~nm}$.

\section{Light shined on only one arm cured rickets in both arms}

From serial views of limb X-ray studies, it was demonstrated that light shined on only one arm cured rickets in both arms. With the aid of radiographs, Huldschinsky studied many cases of rickets in children and how the results were affected by the ultraviolet ray and calcium. He found that under the influence of this type of radiation on one arm, there was a deposition of calcium salts in the ends of the long bones of the two arms which was observable in radiographs. Control children who were not treated with the rays showed no improvement. $\mathrm{He}$ theorized that a chemical was synthesized in response to UV light that could diffuse throughout the affected child [35].

\section{Sun or cod liver oil for the treatment of rickets: experience at the Kinderklinic in Vienna}

At the end of the World War I, rickets was a great problem in Vienna but its real cause was not known. The Medical Research Council of England designed a group led by Harriet Chick [41, 42]. This group went to Vienna for this problem. The different possibilities were all considered: rickets might be caused by diet, by something in water or in the air, or possibly, by an infection. Rickets at the Kinderklinic of Vienna were divided into four groups. Two groups were kept in the ward, while the other groups were kept on the balcony. In the ward, one group received normal diet while the other group received supplementary cod liver oil. Rickets in the latter group of children had healing as demonstrated by Xrays. In the first group, rickets remained sick. On veranda, one group was kept very well covered while the other children, wearing little clothing, were exposed to sunlight. This second group got better. It was demonstrated that the cod liver oil and the exposure to sunlight healed rickets. 


\section{Link between cod liver oil and ultraviolet energy in the treatment of rickets}

The fact that both sunlight exposure (or artificial light) and ingestion of cod liver oil could cure or prevent rickets was perplexing. The link between cod liver oil and radiant energy in the treatment and prevention of rickets had to be explained. This chapter was concluded by a series of experience where the skin was irradiated with ultraviolet light or sunlight.

\section{Determination of the exact antirachitic spectra of ultraviolet radiation}

Hess realized that the antirachitic power of sunlight or of the artificial light was probably limited to a narrow band of ultraviolet radiation. Hess first shown that the exposure to a mercury lamp (spectral range $=230-595 \mathrm{~nm}$ ) prevented rickets in rats when exposed during three minutes at a distance of three feet [43]. The interposition of a filter blocking ultraviolet rays of less than $334 \mathrm{~nm}$ allowed characterization of the antirachitic spectra [44] of ultraviolet radiation: "not exceeding 313 millimicrons [nanometers]." Solar ultraviolet radiation represents less than $1 \%$ of the total solar radiation, and the shortest waves are $290 \mathrm{~nm}$. Therefore, the ultraviolet rays of the sun (290$315 \mathrm{~nm}$ ) have a narrow band that influences the state of vitamin $\mathrm{D}$, bone health, and calcium economy in humans [45].

\section{Relation between food of rats and ultraviolet irradiation of the skin to prevent rickets}

The mechanism of the relation between food of rats and ultraviolet irradiation on rickets was explored with a series of animal experiments, particularly in Hess laboratory [46, 47]. Studies first seemed to demonstrate that the air of irradiated cages of rats (fed with a fat-free diet) could hold the curative factor [48]. However, the investigators had not clean the sawdust from the cages. Harry Steenbock demonstrated that irradiated rats could transfer the curative factor when the nonirradiated rats ate excreta in the sawdust present in the cages or when they licked oils from the fur of the irradiated rats.

\section{Irradiation of the skin of human by ultraviolet radiation is efficient}

Then in 1925, Hess and Weinstock [46] took some excised human skin and, after irradiating it with the mercury-vapor lamp, found that it also conferred immunity against rickets when fed to the rats. The skin not irradiated did not confer any immunity. These experiments at first were interpreted to mean that the active substance was cholesterol. The next few years, however, proved that it was not cholesterol but rather ergosterol.
Milk of mothers, although it does not have a percentage as high as that of cow's milk, is of much more importance in protecting the infant against rickets. Repeated studies have shown that the degree of incidence of rickets is less in those babies nursed by their mothers over those fed on cow's milk or special baby formulas. Hess and Weinstock [47] have found by using human milk on rats that the high power of protection it had against rickets is not due to the antirachitic factor of the milk. Hess and Weinstock found that by irradiating the nursing mother with ultraviolet light, the milk following this irradiation had a high power of antirachitic factor.

\section{The exact nature of sunshine vitamin D}

The chemical nature of vitamin $\mathrm{D}$ needed to be discerned. The vitamin $\mathrm{D}$ precursor, when activated by irradiation, was traced as the sterol fraction in foods, phytosterol for vegetable foods, and cholesterol in animal foods. Hess demonstrated that the phytosterol obtained from the cottonseed oil and that cholesterol obtained from the brain tissue were rendered antirachitic by ultraviolet irradiation. Huldschinsky had shown a decade before that irradiation of one arm could cure the rickets in the other; this suggested that something produced in the skin had to enter into the circulation to impart the cure. With intuition, they hypothesized that the ultraviolet irradiations from the solar rays and from the artificial sources activate cholesterol in the skin and render it antirachitic. They suggested that the mechanism "presupposes not only the formation of active cholesterol in the skin but also its transport by circulation." Hess then collaborated with Adolph Windaus, a German cholesterol specialist, to discern the structure of the fat-soluble vitamin $\mathrm{D}$, showing it was an activated ergosterol product $[48,49]$. It was realized that the vitamin D precursor of the cholesterol rendered antirachitic by UV irradiation was only a contaminant and not the purified cholesterol. Spectroscopic absorption highlighted that the vitamin $\mathrm{D}$ precursor of cholesterol exhibited three different absorption peaks (269 nm, $280 \mathrm{~nm}, 293 \mathrm{~nm}$ ). From these data, the vitamin D precursor fraction was identified as ergosterol, which is found in yeast and fungi (ergot). Irradiated ergosterol (ergocalciferol, calciferol, or viosterol, and vitamin $\mathrm{D}_{2}$ ) was the first photosynthesized antirachitic agent to be discovered.

\section{Consumption of vitamin D-fortified foods (UV radiation) and eradication of rickets}

The idea to trap the sun's radiant energy in foods and render them antirachitic emerged quickly. Steenbock irradiated a large variety of different foods and observed which one could be rendered antirachitic. When they exposed foods to ultraviolet irradiation with a mercury-vapor lamp, the foods allowed growth and calcium assimilation for rachitic rats. Wheat germ, 
lettuce, cottonseed oil, and linseed oil which were deemed inert and ineffective for treating rickets became potent antirachitic agents with ultraviolet irradiation. Hess and Steenbock independently irradiated ergosterol and the green foodstuffs given to rats, which prevented rickets despite a rachitogenic diet [50]. As the antirachitic factor in the irradiated foods was as efficient as cod liver oil, their results were considered as the first demonstration of the production of vitamin in vitro.

Steenbock wanted to patent the irradiation process for ensuring the quality of the commercially produced vitamin Denhanced irradiated foods and to protect Wisconsin dairy industry from the oleomargarine industry. Unlike butter, margarine, a cheap butter substitute, lacked vitamin A and vitamin $\mathrm{D}$; however, the margarine could be fortified with vitamin $\mathrm{A}$. Steenbock (Fig. 17) was convinced that the process for vitamin D enrichment needed to be protected. Steenbock asked the Wisconsin University to manage his patents. Realizing the prospects of Steenbock's discovery, Harry L. Russell, the dean of the College of Agriculture, and Charles S. Slichter, the dean of Graduate School, convinced several alumni for creating an independent organization able to handle the patents [50-54]. Steenbock patented the irradiation process and was able to develop a technique by which ergocalciferol was added to milk and other dairy products [51]. The supplement was set at $400 \mathrm{IU}(10 \mu \mathrm{g})$ per 1 , the amount found in a teaspoonful of cod liver oil of the time [52]. Thus, the Wisconsin Alumni Research Foundation (WARF) was founded on 14 November 1925, to administer Steenbock's patents. WARF [51] granted the licenses for the irradiation process and was an intermediary between the university and commerce. It ensured the quality of irradiated products generated from the licenses was exclusively used for promotion of research at the University of Wisconsin. Quaker Oats received in February 1927 the first license from WARF to manufacture vitamin $D$-enriched breakfast cereal.

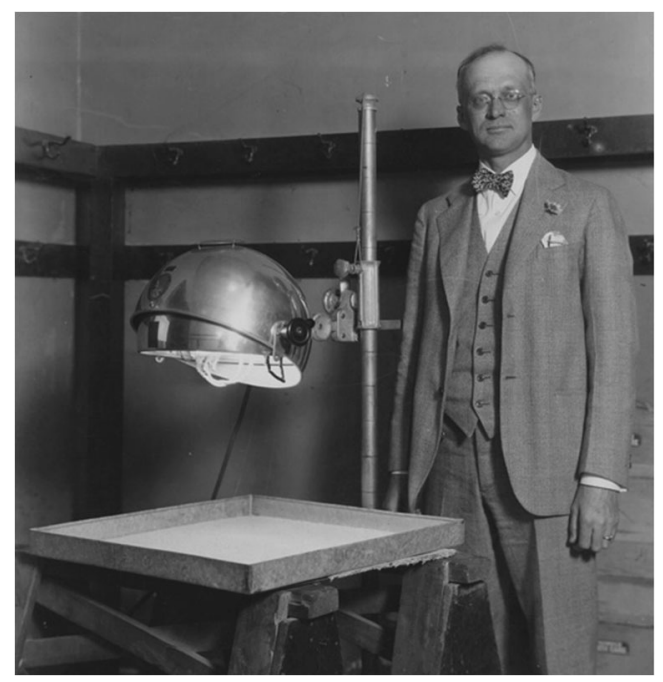

Fig. 17 Portrait of Steenbock with his lamp

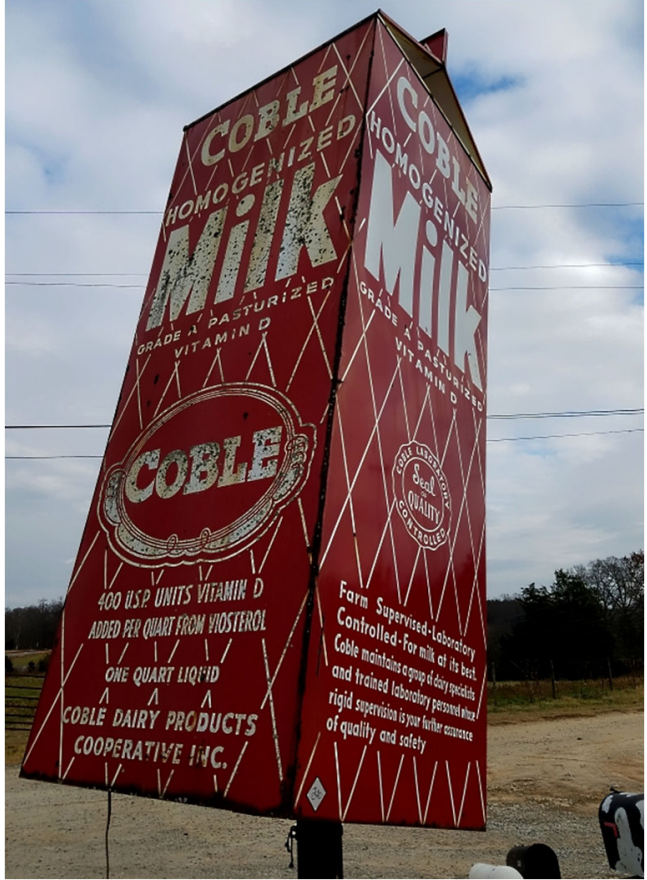

Fig. 18 Publicity for milk with vitamin D (1934)

Licenses were issued to several pharmaceutical companies (Mead Johnson, Abbott Laboratories, Winthrop Chemical Co, Parke Davis, and Squibb) to manufacture a medicinal vitamin $\mathrm{D}$ that was called viosterol (irradiated ergosterol). The irradiation process was extended in 1934 to produce a vitamin Dfortified milk. Vitamin D fortification was therefore achieved inexpensively by adding the vitamin D directly to milk (Fig. 18). It was possible to enhance the content of common

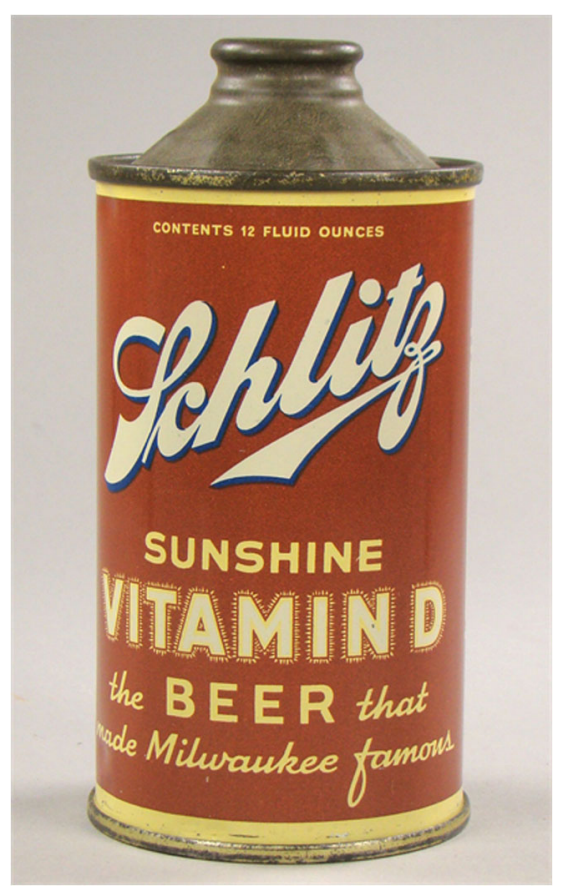

Fig. 19 Can of Schlitz "Sunshine Vitamin D" beer (1936) 
infant foods (milk and cereal) with vitamin D in an inexpensive way. Consumption of such vitamin $D$ foods led to eradication of epidemic rickets. People were advised to take a daily dose of sunshine in their diet. Within two decades, a large variety of foods were fortified with vitamin $\mathrm{D}$, including bread, custard, hot dogs, soda, and even beer (Fig. 19)! The advent and consumption of vitamin D-fortified foods led to eradication of rickets. This was a public health triumph.

\section{Conclusion}

In the early twentieth century, before diagnosis or treatment had been fully standardized and before the scientific research had been completed, many people debated the aetiology of rickets. Some saw the disease as the price of urbanization. Multiple studies between 1917 and 1925 worked to standardize diagnosis treatment and prevention regimes. With increasing dependence on the new technology of the X-ray in the context of preventive medicine, rickets was redefined as a very frequent disease in children. Rickets therefore provides an excellent window in the early politics of preventive health in the world and an historical counterpoint for current debates over the role of risk factors (absence of light or sun) for disease (today's so-called "lifestyle" diseases). It was also used to promote young disciplines of preventive medicine, paediatrics, or public health.

\section{Compliance with ethical standards}

Conflict of interest The authors declare that they have no conflict of interest.

Publisher's Note Springer Nature remains neutral with regard to jurisdictional claims in published maps and institutional affiliations.

\section{References}

1. Hernigou P, Auregan JC, Dubory A (2018) Vitamin D: part I; from plankton and calcified skeletons (500 million years ago) to rickets. Int Orthop. Mar 5. https://doi.org/10.1007/s00264-018-3857-3

2. Schmorl G. (1909) Ergeb inn Med u Kinderheilk, 4, pp. 403-454.

3. Fedotoff P A (1842) De oleo Jecoris Aselli, Diss. Leipsic,.

4. Pliny the Elder (born Gaius Plinius Secundus, AD 23-79) Nat. Hist., Lib. 32, p. 27.

5. Browne T (1663) The works of Sir Thomas Browne 1931. In: Keynes G (ed) Notes on the natural history of Norfolk, chiefly birds and fishes, circa. vol 5. Faber and Faber, London, p 385

6. Percival T (1790) Percival's essays, Ed. 4, 2:360,

7. Hufeland's Journal (1822) 56:128.

8. Schenck D (1822) J. d. pract. Heilk. 55:31, Part 6.

9. Schutte D (1824) Archiv fur medizinche Erfahrung:79

10. Schenck. (1826) Neues Journal der practischen Arzneykunde und Wundarzneykunst, 62 III. Stuck p 3.26A.

11. De V (1836) Schmidt's Jahrb 5:147
12. Trousseau A (1868) Lectures on clinical medicine, delivered at the Hôtel-Dieu, Paris, 3rd edn. Translated by Sir John Cormack. New Sydenham Society, London, p 1872

13. Bland SJ (1889) Rickets in monkeys, lions, bears and birds. J Comparat Surg 10:1-29

14. Fraenkel E, Lorey A (1910) Archiv und Atlas der normalen und pathologischen Anatomie in typischen Rontgenbild. Lucas Grafe and Sillem, Hamburg

15. Lovett RW (1915) The roentgenographic appearances in rickets. JAMA 65:2062

16. Rosen G (1975) The case of the consumptive conductor, or public health on a streetcar: a centennial tribute to Alfred F. Hess, MD. Am J Public Health 65:978

17. Hess AF, Unger LJ (1917) Prophylactic therapy for rickets in a Negro community. J Am Med Assoc 69:1583-1586

18. Mellanby E (1918) The part played by an "accessory factor" in the production of experimental rickets. J Physiol 52:11-14

19. Mellanby E (1919) An experimental investigation on rickets. Lancet 1:407-412

20. McCollum EV, Simmonds N, Becker JE, Shipley PG (1922) Studies on experimental rickets XXI: an experimental demonstration of the existence of a vitamin which promotes calcium deposition. J Biol Chem 53:293-312

21. Kramer B, Casparis H, Howland J (1922) Ultraviolet radiation in rickets. Effect on the calcium and inorganic phosphorus concentration of the serum. Am J Dis Child 24:20-26

22. Powers GF, Park EA, Shipley PG, McCollum EV, Simmonds N (1921) The prevention of the development of rickets in rats by sunlight. In Proceedings of the American Child Hygiene Association Transactions of the 12th annual meeting, New Haven, CT, USA; pp. 74-91.

23. Parkes EA (1923) Etiology of rickets. Physiol Rev 106-163:143144

24. Sniadecki J D (1840) vol 1; 273-274 Warszawa

25. Mozolowski W (1939) Jędrzej Sniadecki (1768-1838) on the cure of rickets. Nature 143. https://doi.org/10.1038/143121a0.

26. Ekpe J (2009) The chemistry of light: the life and work of Theobald Adrian Palm (1848-1928). J Med Biogr 17:155-160

27. Hirsch A (1886) Handbook of geographical and historical pathology. The New Sydenham Society, London, pp 732-741

28. Palm TA (1888) Letter to the editor. Br Med J 2:1247

29. Owens I (1889) Reports of the Collective Investigation Committee of the British Medical Association. Geographical distribution of rickets, acute and subactute rheumatism, chorea and urinary calculus in the British Islands. Br Med J 1:113-116

30. Palm TA (1890) The geographical distribution and etiology of rickets. Practitioner 45:270-342

31. Rollier A (1923) Heliotherapy. Henry Frowde and Hodder \& Stoughton, London, England

32. Raczynski J (1913) Recherches Experimentales sur le Manque D'action au Soleil Comme Cause du Rachitisme; C. R. Assoc. Internat. Pediatrie: Paris, France; pp. 308-309.

33. Buchholz E (1904) Ueber Lichthandlung der Rachitis und andere Kinderkrankheiten. In Verhandlungen der Gesellschaft fur Kinderheilkunde in der Abteilung fur Kinderheilkunde der 76 Versammlung der Gesellschaft Deutscher Naturforscher und Aerzte in Breslau, Breslau, Germany; Volume 21, p. 116.

34. Mills A (2013) The Nernst lamp. Electrical conductivity in nonmetallic materials. Rittenhouse 24(1) Archived from the original on 17 July 2013

35. Huldschinsky K (1919) Heilung von rachitis durch kunstliche hohensonne. Dtsch Med Wochenschr 45:712-713

36. Huldschinsky K (1920) Die behandlung der rachitis durch ultraviolet bestrahlung. Ztschr f Orthop Chir 39:426

37. Riedel G (1920) Die Erfolge der quartzlichtbestrahlung bei rachitis. Munchen Med Wochenschr 67:838 
38. Heraeus-Hanau H (1903) Über Quarzglas. Z Elektrochem 9:847850

39. Schott O (1905) Eine Neue Ultra violett queck silber lampe. Uviollampe. Chem Zentralblatt, I:76-77

40. Schott O (1905) A new ultra-violet mercury lamp. Nature:513-514

41. Chick H, Dalyell EJ, Hume M, Mackay HMM, Henderson-Smith H, Wimberger H (1922) The aetiology of rickets in infants. Lancet $2: 7-11$

42. Medical Research Council (1923) Studies of rickets in Vienna. HMSO, London, pp 1919-1922

43. Hess AF. (1922) Influence of light in the prevention and cure of rickets. Lancet.;ii:367. Reprinted in: Hess AF. Collected writings. Vol 2. Springfield, Ill: Charles C. Thomas; 1936:5-14.

44. Hess AF, Weinstock M (1923) A study of light waves in their relation to rickets. JAMA 80:687-690

45. Hess AF. (1925) The ultraviolet rays of the sun. JAMA.;84:1033. Reprinted in: Hess AF. Collected writings. Vol 2. Springfield, Ill: Charles C. Thomas; 1936:167-178.

46. Hess AF, Weinstock M (1925) The antirachitic value of irradiated cholesterol and phytosterol. II. Further evidence of change in biological activity. J Biol Chem 64:181-191

47. Hess AF, Weinstock M (1924) Antirachitic properties imparted to inert fluids and to green vegetables by ultra-violet irradiation. J Biol Chem 62:301-313
48. Windaus A, Hess A (1927) Sterine und Antirachitisches Vitamin. Weidmannsche Buchhandlung, Berlin, pp 175-184

49. Hess AF, Windaus A (1927) The development of marked activity in ergosterol following ultraviolet irradiations. Exp Biol Med 24:461462

50. Steenbock H (1924) The induction of growth promoting and calcifying properties in a ration by exposure to light. Science 60:224 225

51. WARF (2011) Wisconsin Alumni Research Foundation.. Available online: http://www.warf.org. Accessed July 2018

52. Schneider HA (1973) Steenbock H (1886-1967) - a biographical sketch. J Nutr 103:1233-1247

53. Steenbock H, Nelson MT (1924) Fat soluble vitamins XIX: the induction of calcifying properties in a rickets-producing ration by radiant energy. J Biol Chem 62:209-216

54. Steenbock H, Black A (1925) The induction of growth promoting and calcifying properties in a ration by exposure to ultra-violet light. J Biol Chem 64:263-298

This is a historical paper. 